Research article

\title{
Risk aversion and willingness to pay for water quality: The case of non-farm rural residents
}

\author{
Bruno Larue, PhD ${ }^{\mathrm{a},{ }^{*}, \text { Gale E. West, } \mathrm{PhD}}{ }^{\mathrm{a}}$, Alphonse Singbo, PhD ${ }^{\mathrm{b}}$, \\ Lota Dabio Tamini, $\mathrm{PhD}^{\text {a }}$ \\ ${ }^{a}$ Center for Research on the Economics of the Environment, Agri-food, Transports and Energy (CREATE), University Laval, 2425 de l'Agriculture St., Québec, \\ QC G1V0A6, Canada \\ ${ }^{\mathrm{b}}$ International Crops Research Institute for the Semi-Arid Tropics, Bamako, Mali
}

\section{A R T I C L E I N F O}

\section{Article history:}

Received 7 September 2016

Received in revised form

10 March 2017

Accepted 17 March 2017

\section{JEL codes:}

Q25

Q51

R11

Keywords:

Water quality

Willingness-to-pay

Risk aversion

Rural residents

\begin{abstract}
A B S T R A C T
Stated choice experiments are used to investigate the economic valuation of rural residents living in the province of Quebec for water quality improvements. In Quebec, rural residents played an important role in the setting of stricter environmental regulations. Unlike most stated choice experiments about the valuation of improvements in water quality, this study explicitly accounts for risk in the design and analysis of choice experiments. Risk in phosphorus and coliform reductions is introduced through a three-point uniform distribution in the choice sets. The results show greater support for constant absolute risk aversion preferences than for constant relative risk aversion. Rural residents value coliform and phosphorus reductions and the more educated ones are particularly willing to see the government tax farmers and taxpayers to secure such reductions. As the science improves and risk in water quality outcomes decrease and as the political weight of non-farm rural residents increase, it should be easier for governments to replace voluntary cost-share programs by polluter-payer programs.
\end{abstract}

(c) 2017 Elsevier Ltd. All rights reserved.

\section{Introduction}

Agricultural activities have adverse environmental effects that can be mitigated by the adoption and implementation of Best Management Practices (BMPs henceforth). Intensive farming can trigger significant releases of pollutants into ditches, streams and groundwater that impact on water quality at the watershed level. Studies identified that excessive phosphorus loads is the major cause of blooms of blue-green algae in lakes and reservoirs (Lathrop et al., 1998). ${ }^{1}$ Blue-green algae blooms are associated with episodes of toxicity, fish kills, anoxia, and generally noxious

\footnotetext{
* Corresponding author.

E-mail addresses: bruno.larue@eac.ulaval.ca (B. Larue), gale.west@eac.ulaval.ca (G.E. West), alphonse.singbo@gmail.com (A. Singbo), Lota.tamini@eac.ulaval.ca (L.D. Tamini)

${ }^{1}$ Blue-green algae is a common name for cyanobacteria which relies on photosynthesis to grow and incidentally is not an algae. Blue-green algae is not always dangerous, but some may produce neurotoxins and hepatotoxins which attack the nervous system and the liver. Garnache et al. (2016) review the state of knowledge about phosphorus pollution and identify research gaps in various areas that need to be filled to design and implement better abatement strategies in the US.
}

shoreline conditions resulting from wind-blown accumulations of algae during the summer and as a result, the public's perception of water quality in lakes is often associated with the frequency of alga blooms. The Chaudière region south of Quebec City is one where water quality is a major concern. Excess phosphorus in this region and in others has spurred opposition to large scale hog operations.

In Quebec, a province-wide moratorium on new hog facilities, including expansion projects, was put in place between 2002 and 2005. This policy did not reduce production in areas with excess phosphorus, but it gave time to the authorities to develop more coherent regulations and policies. For example, farmers must produce a phosphorus report ${ }^{2}$ to participate in a revenue insurance program and to get a property tax credit. They are also required to have a sustainable fertilization plan prepared by an agronomist and public hearings must be held before new hog production projects

\footnotetext{
2 The report is an inventory of both produced and imported phosphorus loads and the capacity of soils to handle these loads in compliance with the maximum annual phosphorus deposits prescribed. More details are available at: http://www. mddelcc.gouv.qc.ca/milieu_agri/agricole/phosphore/bilan-en.htm.
} 
can be implemented. The federal and provincial governments have also promoted the adoption of specific BMPs like crop rotations, surface runoff controls, reduced herbicide use, solid and liquid manure management with adoption rates ranging from $15 \%$ to $66 \%$ (Ghazalian et al., 2009). Government programs were underperforming in meeting sustainable development objectives and tensions between farmers and rural residents remained in spite of the additional regulations imposed on farmers (MDDEP, 2011a). A new approach was needed and in 2013, Quebec's provincial government introduced a new integrated water management program at the watershed level that provides funding to watershed organizations. The latter bring together representatives of regional county municipalities (RCM), municipalities, users, environmental groups and citizens. Watershed organizations are eligible to receive funding, up to $\$ 30,000 \mathrm{CAD} / \mathrm{year}$, to tackle well-documented water quality problems. A farmer involved in a collective program can also receive cost-share funds covering $70 \%$ of eligible expenses or $90 \%$ of eligible expenses if a neighbor farmer whose land borders his, also applies for cost-share funds. ${ }^{3}$ It is hoped that farmers and citizens working together will be able to develop more efficient interventions (MDDEP, 2011b). Taxpayers contributions toward BMP adoption is substantial and it is on this issue that this paper focuses by investigating the preferences of rural residents, excluding farmers, when it comes to trade-offs involving coliform and phosphorus reductions and added costs for taxpayers and farmers. ${ }^{4}$

Unlike previous stated choice experiments about water quality, this study explicitly accounts for risk in the design and analysis of choice experiments. As such, it is hypothesized that support for investments to improve water quality is conditioned by the expected improvement in water quality, but also by the distribution of possible improvements. More specifically, this study investigates the role of risk aversion ${ }^{5}$ on willingness-to-pay estimates for water quality improvements. The expected utility (EU) theory has a long tradition in the analysis of decisions under risk. It revolves around the valuation and probability of different outcomes. One of the challenges in introducing risk aversion is to describe the outcomes and the probabilities in a succinct yet transparent manner (Palsson, 1996). This is accomplished by showing respondents 3-point discrete uniform distributions with different means and spreads about reductions in coliforms and phosphorus. Because the lower and upper bounds are equally distant from the means and each proposed reduction has the same probability, the mean reduction and the spread can be seen as attributes. Two utility functions incorporating risks are estimated. The first one posits that risk preferences display constant absolute risk aversion (CARA) while the second showcases constant relative risk aversion (CRRA). Different specifications are estimated with fixed and random parameters to assess the robustness of the results and to address observed and unobserved heterogeneities across respondents. One set of regressions allows unobserved heterogeneity in risk aversion while cost coefficients are fixed. A second set of regressions has fixed risk aversion coefficients, but allows for unobserved heterogeneity in costs.

To summarize, this article aims to analyze the preferences of non-farm rural residents, about water quality improvements and how the cost for such improvements should be divided between

\footnotetext{
${ }^{3}$ For the details of the program, see http://www.gcaq.ca/client/uploads/179/ 68184964294112.pdf.

${ }^{4}$ Excess phosphorus is a global problem and increasing on-farm phosphorus efficiency is costly. Sharpley et al. (2015) discuss various policy options to internalize environmental costs in decisions made by farmers and consumers.

5 Hirshleifer and Riley (1992, p.23) define a risk averse person as someone who "prefers a certainty consequence to any risky prospect whose mathematical expectation of consequences equals that certainty."
}

farmers and taxpayers. Risk in BMPs capacity to improve water quality as well as observed and unobserved heterogeneity in risk attitudes on the part of rural residents are taken into account. The research relies on stated-choice experiments involving 711 randomly-selected non-farm rural residents from the Chaudière region south of Quebec City.

The remainder of this paper is organized as follows. Section 2 reviews the literature on the adoption of BMPs and growing social and economic importance of rural residents. Section 3 presents the research methodology with subsections on expected utility theory, random utility models and the choice design behind the stated choice experiments. Section 4 presents the estimation results and the trade-offs between attributes like willingness to pay for expected coliform and phosphorus reductions and meanstandard deviations. Section 5 discusses the policy implications and limitations of our study.

\section{The growing influence of rural residents and BMPs}

The literature on BMP adoption focuses on farmers' characteristics and their farms (e.g., Baumgart-Getz et al., 2012). Tamini (2011) and Hadrich and Van Winkle (2013) find that extension services increase the probability of BMP adoption. Rahelizatovo and Gillespie (2004) and Hadrich and Van Winkle (2013) contend that problem awareness impacts on BMP adoption. Asci et al. (2015) argue that the incidence of BMPs on the mean and variance of profit and farmers' attitude toward risk condition adoption. Ghazalian et al. (2009) find that larger farms are more likely to adopt BMPs because they can more easily afford implementation $\operatorname{costs}^{6}$ and are more often the object of criticism regarding the adverse effects of agricultural production. Reimer et al. (2012) did in-depth interviews with Indiana farmers and found that those who care about off-farm environmental benefits and feel responsible to others are most likely to adopt BMPs. Clearly, most farmers care about how they are perceived by nonfarm rural residents.

The importance of rural residents as a proportion of the rural population is rising rapidly. In Quebec, the last census reveals that rural population increased from 1,420,330 in 2001 to $1,534,731$ in 2011 with an annual average increase rate of $0.81 \%$ while the number of farms decreased from 32,139 to 29,437 over the same period (indicating an annual decrease rate of $0.92 \%){ }^{7}$ A similar pattern applies for Canada as a whole. This trend has interesting political economy implications. Farmers must be increasingly sensitive to the preoccupations and expectations of rural residents. New institutions are being created to reflect the growing political power of rural residents. The aforementioned integrated water management approach that empowers rural residents in the decision-making process about environmental initiatives applied at the watershed level is clearly a step in this direction. Rural residents can directly benefit from BMP adoption by farmers ${ }^{8}$ and that these benefits are valuable. For example, Luzar and Cossé (1998) find that having a private well tends to increase the willingness to pay for one's own and state-level water quality.

\footnotetext{
${ }^{6}$ Ghazalian et al. (2010) and Tamini et al. (2012) find that BMPs tend to slightly increase costs/decrease profit, but Valentin et al. (2004) find that the adoption of nutrient BMPs has a positive effect on net farm income. Hadrich and Van Winkle (2013) find that farms with low debt loads are more likely to adopt BMPs.

${ }^{7}$ For rural population statistics, see http://www.statcan.gc.ca/tables-tableaux/ sum-som/101/cst01/demo62f-eng.htm and for the number of farms see http:// www.omafra.gov.on.ca/english/stats/census/number.htm.

8 Rural residents may also adopt BMPs for homeowners, a subject investigated by
} Brehm et al. (2013). 


\section{Research methodology}

The aim of this study is to investigate rural residents' preferences about coliform and phosphorus in water stemming from the implementation of BMPs. One of our objectives is to ascertain whether dispersion around predicted reductions impacts on the valuation of coliform and phosphorus reductions by rural residents and if so, to measure the risk aversion of rural residents. Another objective is to evaluate the extent by which rural residents are willing to have farmers and taxpayers contribute financially to achieve coliform and phosphorus reductions. Our analysis relies on stated choice experiments which are most useful to estimate the value of goods and services in the absence of market data. The idea is to present choice sets to respondents and to extract information about their preferences from the choices they make. Our introduction of risk in stated choice experiments is grounded in expected utility theory (EUT). The next subsection describes the concept and two common types of risk preferences.

\subsection{The valuation of pollution reductions under risk}

EUT has a long tradition in applied economics to analyze behavior in the presence of risk. It assumes that respondents know the probabilities and benefits associated with each possible outcome and simply sums up the expected benefits when evaluating a given scenario. Respondents were confronted to three equally probable contingent reductions in phosphorus (p) and in coliforms (c): $r_{k}-d_{k}, r_{k}, r_{k}+d_{k}$ with $k=\mathrm{p}, \mathrm{c} ; r_{k}$ is the mean reduction and $d_{k}$ is the discrete interval and the spread is then $2 d_{k}$. All else equal, risk averse respondents prefer less to more dispersion. Utility functions allowing for risk aversion must be specified and their non-linearity adds complexity (Glenk and Colombo, 2013; Palsson, 1996). Two popular forms of risk aversion are considered. Constant absolute risk aversion behavior is characterized by the utility function $(U): \quad U=1-e^{-\gamma r}$, with $A R A \equiv \frac{-\partial^{2} U / \partial r^{2}}{\partial U / \partial r}=\gamma$, $R R A \equiv \frac{-\partial^{2} U / \partial r^{2}}{\partial U / \partial r} r=\gamma r$, where ARA and RRA are respectively the Arrow-Pratt coefficients of absolute and relative risk aversion. CARA implies that risk aversion is constant, regardless of the size of the pollution reductions considered. With three equal probabilities, expected utility can be expressed as:

$$
\begin{aligned}
E U= & \frac{\left(3-\mathrm{e}^{-\left(d_{p}+r_{p}\right) \gamma_{p}}\left(1+\mathrm{e}^{d_{p} \gamma_{p}}+\mathrm{e}^{2 d_{p} \gamma_{p}}\right)\right)}{3} \\
& +\frac{\left(3-\mathrm{e}^{-\left(d_{c}+r_{c}\right) \gamma_{c}}\left(1+\mathrm{e}^{d_{c} \gamma_{c}}+\mathrm{e}^{2 d_{c} \gamma_{c}}\right)\right)}{3}+\sum_{j=1}^{J} \beta_{j} x_{j}
\end{aligned}
$$

Variables $x_{j}$ are fixed and include monetary variables like cost and other attributes. As specified, attitude toward risk can differ whether risk is about phosphorus or coliform reductions. When allowed to be random, a cost parameter $\beta_{\cos t}$ can be replaced by $-e^{\beta_{\cos t}}$ to insure that the effect of cost on utility is strictly negative. Risk preferences that exhibit constant relative risk aversion (CRRA) also exhibit decreasing absolute risk aversion (DARA). This means that dispersion induces less disutility around large expected pollutant reductions than around small ones. The corresponding utility function is: $U(r)=\frac{r^{1-\gamma}}{1-\gamma} ; \gamma \in(0,1]^{9}, A R A=\frac{\gamma}{r}, R R A=\gamma$. When $\gamma=0, U=r$ and agents are risk neutral while when $\gamma>0$, agents

\footnotetext{
${ }^{9}$ In practice, the estimate of $\gamma$ may not fall within the $0-1$ bounds. A logistic transformation can be used to insure that the estimate falls within the bounds or else inequality restrictions can be imposed in a Bayesian framework.
}

are risk averse. ${ }^{10}$ Expected utility can be depicted by ${ }^{11}$ :

$$
\begin{aligned}
E U= & \frac{r_{p}^{1-\gamma_{p}}+\left(-d_{p}+r_{p}\right)^{1-\gamma_{p}}+\left(d_{p}+r_{p}\right)^{1-\gamma_{p}}}{3\left(1-\gamma_{p}\right)} \\
& +\frac{r_{c}^{1-\gamma_{c}}+\left(-d_{c}+r_{c}\right)^{1-\gamma_{c}}+\left(d_{c}+r_{c}\right)^{1-\gamma_{c}}}{3\left(1-\gamma_{c}\right)}+\sum_{j=1}^{J} \beta_{j} x_{j}
\end{aligned}
$$

Rural residents may be risk averse at different degrees and a parsimonious way to accommodate this heterogeneity is to rely on a random parameter logit (RPL). The RPL estimator is briefly discussed in the next subsection.

\subsection{Preference heterogeneity in empirical models}

Random utility models (RUMs) have been used extensively to characterize the preferences of respondents from the choices they make in stated choice experiments. Under RUM, respondents can assess the value of different attributes and hence choose alternatives that provide them the highest level of utility. From the estimated coefficients of utility functions, willingness-to-pay (WTP) estimates can be generated, but their usefulness could be impaired if heterogeneity in preferences is not properly accounted for (Campbell et al., 2013). The RPL assumes a continuous distribution for a subset of parameters in dealing with heterogeneity across respondents. McFadden and Train (2000) demonstrate that any random utility model can be approximated by a mixed logit with the appropriate choice of variables and mixing distribution. The formulation of the RPL model decomposes utility into an unobserved, preference heterogeneity component and a deterministic component. In each choice set $t$, respondent $i$ chooses the alternative that yields the highest utility amongst the $j$ alternatives. The respondent chooses the alternative that maximizes his or her utility in each choice occasion. The random utility of respondent $i$ is defined as: $U_{i j t}=\beta X_{i j t}+\eta_{i} X_{i j t}+\varepsilon_{i j t}$ where $X_{i j t}$ is a vector of observed alternative-specific attributes including the mean and the standard deviation of phosphorus and coliform reductions, $\beta$ is the vector of coefficients associated with these attributes, and $\eta_{i}$ is a vector of $k$ standard deviation parameters. $\varepsilon_{i j t}$ is a stochastic term that is assumed to be an independent and identically distributed extreme value (Gumbel distributed). Under this specification each respondent has his or her own vector of parameters, $\beta_{i}$, which deviates from the population mean, $\beta$, by the vector $\eta_{i}$. Assuming that the unconditional density $f(\beta \mid \vartheta)$ has a continuous distribution, the unconditional probability of the observed sequence of choices is $\operatorname{Pr}_{i}(\vartheta)=\int \prod_{t=1}^{T} \prod_{j=1}^{J}\left\{\frac{\exp \left(\beta x_{i j t}\right)}{\sum_{k=1}^{J} \exp \left(\beta x_{i k t}\right)}\right\}^{d_{i j t}} f(\beta \mid \vartheta)$. This probability defines a mixed logit model with continuous mixing distributions and the related log-likelihood function is fitted with simulation methods. Conditional on how the $\beta$ coefficients are distributed over the population, Train (2003) shows that the simulated probability is an unbiased estimator of $\operatorname{Pr}_{i}$ and that its variance decreases as the number of draws used to simulate the probability increases. ${ }^{12}$ Heterogeneity amongst respondents can also be conditioned by observable variables such as socio-demographic variables and

\footnotetext{
${ }^{10}$ When $\gamma=1, U(r)=\log (r)$, RRA $=1$.

11 When there are only two contingencies, $r$ and 0 , with probabilities $p$ and $1-p$, as in Glenk and Colombo (2013), the EU isoelastic specification reduces to: $E U=p \frac{r^{\gamma}}{1-\gamma}$. 12 Hanley et al. (2006) contend that marginal utilities of environmental attributes are likely to be correlated and that it is best when possible to allow for random coefficients to be correlated.
} 
perceptions of respondents. It is assumed that the random parameters are distributed according to a multivariate normal distribution to allow for correlation between random parameters. Some coefficients are usually assumed fixed to facilitate convergence and the interpretation of welfare measures (Colombo et al., 2009; Hensher et al., 2005).

\subsection{Study design and data}

When it comes to agri-environmental policies and more specifically to BMPs, questions arise about who should pay, who should implement BMPs, and which BMPs should be implemented. There have been many studies investigating taxpayers' willingness to pay (WTP) for improvements in water quality (e.g., Kosenius, 2010). WTP for water quality tends to be higher for people living close to polluted water. This is why our sample consists of non-farm rural residents. Furthermore, our study design allows for water quality improvements to be funded by taxpayers and/or farmers as rural residents might favor the pay-the polluter or the polluter-payer principles. The farmers' contribution is expressed in \$/acre CAD, but in the instructions to respondents, it has been mentioned that a $\$ 10 /$ acre meant a contribution of $\$ 3000$ for a 300 -acre farm which is roughly the average acreage in Quebec. ${ }^{13}$ Secondly, as stated above, we bring risk in the delivery of water quality improvements which take the form of percentage reductions in phosphorus and coliform. ${ }^{14}$ These elements were incorporated into the design of the stated preference survey which benefitted from comments and suggestions from extension agents, farmers and rural residents who met with us and participated in a pretest experiment.

The final design of the study comprised of 12 choice sets, which were blocked into two small designs, such that each respondent was required to complete a panel of six choice sets. ${ }^{15}$ The choice set design was developed with NGene (NGene, 2012). As shown by Colombo et al. (2016) in choice experiment, inconsistencies choice has a great impact on the welfare measures. In that respect, a Defficient design was used to optimize on the precision of the parameters to be estimated. ${ }^{16}$ For each choice set, respondents were asked to choose between two experimentally designed alternatives and a status quo alternative. When making their choices, respondents were asked to consider only the information presented in the choice set and to treat each set separately. Fig. 1 shows an example of a choice set. It is seemingly made up of four attributes, namely phosphorus reductions, coliform reductions, taxpayers' cost and farmers' cost, but there are actually six attributes because three equally probable reductions are proposed instead of a deterministic one when describing reductions in phosphorus and

\footnotetext{
13 Taxpayers' costs are expressed in dollars per taxpayer, but in our instructions to respondents it was stated that a $\$ 2$ contribution would amount to a $\$ 12$ million investment in water quality.

14 Percentage reductions have been used as public policy targets by the Quebec and Vermont governments and they have also been used to describe BMP performance by hydrologists (Michaud et al., 2007). Percentages were used to portray water quality improvements because they are easy to understand by respondents who had to evaluate several attribute trade-offs embodied in the choice sets. The percentages in the choice sets were based on documented BMP effects in Quebec. For example, Meals et al. (2010) report that reduced fertilizer rates brought down $P$ concentrations from $394 \mathrm{~kg}$ P ha-1 to 270,281 , and $294 \mathrm{~kg} P$ ha-1, or reductions of 25-30\%, while Michaud et al. (2007, p.339) argue that "the adoption of conservation tillage on all HRUs cropped to corn or soybean, combined with intercropping of leguminous forages and small grains within the watershed, would result in a $35 \%$ predicted drop in P loads from the watershed's cropped lands".

15 This is a standard technique used to reduce the number of choices (Louviere et al., 2000, p. 83-137).

16 Rose et al. (2008) report statistical evidence indicating that D-efficient designs outperform traditional orthogonal designs in estimating the utility parameters in stated choice experiments. The D-error for our design was 0.001435 .
}

\begin{tabular}{|l|c|c|c|}
\hline Attribute & Practice \# 1 & Practice \# 2 & Current practice \\
\hline $\begin{array}{l}\text { Probable reductions } \\
\text { in phosphorus }\end{array}$ & $30 \%$ or $40 \%$ or $50 \%$ & $0 \%$ or $20 \%$ or $40 \%$ & \\
\hline $\begin{array}{l}\text { Probable reductions } \\
\text { in coliform }\end{array}$ & $0 \%$ or $15 \%$ or $30 \%$ & $25 \%$ or $35 \%$ or $45 \%$ & \multirow{2}{*}{ No change } \\
\hline Farmers' cost & $\$ 10$ per acre & \$25 per acre & \\
\hline Taxpayers' cost & $\$ 18$ per year & $\$ 2$ per year & \\
\hline $\begin{array}{l}\text { Please tick the one } \\
\text { option you prefer }\end{array}$ & & & \\
\hline
\end{tabular}

Fig. 1. Sample choice set.

in coliform. The 3-point discrete uniform distribution conveys, in a most transparent fashion, information about the dispersion around the expected reduction (since the standard deviation is a monotone transformation of the spread or the difference between the maximum and minimum reductions) without having to explain concepts of dispersion to respondents (Table 1). The level of education is a categorical order variable ranging from 1 to 5 . The score of one indicates 'primary level' where the score of 5 is associated with 'post-graduate level'. ${ }^{17}$

The sample was made up of rural residents in the province of Quebec. The survey instrument was pretested with 50 respondents to insure that questions were phrased properly, that the stated choice experiments were correctly specified ${ }^{18}$ and that the overall length of the exercise was reasonable. Participants were also given pecuniary incentives to complete the survey. Data were collected from 976 rural residents, but after deleting incomplete surveys and observations that are considered as highly inconsistent in order to reduce the effect of inconsistence choices of the WTP, the total number of respondents dropped to 711 , yielding to 4266 completed choice sets and 12,798 observations in the panel. Response consistency is assessed by a number of questions, which allowed identification of individuals, who always chose the expensive alternative or the status quo in all experiments. The survey was conducted during the spring of 2012 via internet by a specialized firm.

\section{Results and discussions}

Table 2 presents summary statistics for the sample. Approximately $56 \%$ of the respondents were women. The average age in the group was 48 years old and two thirds was between 40 and 70 years old. A large proportion of the respondents (72\%) had posthigh school education. In all, $13 \%$ of the respondents had an annual personal income of less than $\$ 25,000$, a percentage of $72 \%$ had an annual income between \$25,000 and \$100,000 and 15\% earned at least $\$ 100,000$. In terms of gender, age and income, the sample is quite similar to the population of rural residents in the province of Quebec which is characterized by a 60-40 women-men ratio, an average age of 48 , and a proportion of persons with an annually personal income less than $\$ 25,000$ of $15 \%$ (Statistics Canada, 2011).

\footnotetext{
17 Estimations with educational dummy variables were compared to estimations with a single education variable. Education effects were monotone and similar across specifications and the more parsimonious specification was retained for the computations of marginal effects.

18 The layout should be clear and the choice set design and parameters should be such as to produce tradeoffs, reduce the likelihood of dominant alternatives, and enable us to accurately estimate preference parameters to compute WTP estimates.
} 
Table 1

Attributes and their levels.

\begin{tabular}{|c|c|c|c|}
\hline Attributes & Variable name & Units & Levels \\
\hline Expected phosphorus reduction & $\mathrm{P}$ & $(\%)$ & $0,15,20,25,30,35,40$ \\
\hline Expected coliform reduction & $\mathrm{C}$ & $(\%)$ & $0,15,20,25,30,35,40$ \\
\hline Half spread around expected phosphorus reduction & STD_P & $(\%)$ & $0,5,10,15,20$ \\
\hline Half spread around expected coliform reduction & STD_C & (\%) & $0,5,10,15,20$ \\
\hline Farmers' $\operatorname{cost}^{\mathrm{a}}$ & $\mathrm{F}$ & (\$CAD/acre) & $-5,0,10,25,35$ \\
\hline Taxpayers' cost & $\mathrm{T}$ & (\$CAD/year) & $0,2,10,18$ \\
\hline
\end{tabular}

a The negative value $(-5)$ of Farmers' cost means farmers will earn a profit of \$5 CAD per acre.

Table 2

Sample summary statistics.

\begin{tabular}{|c|c|c|c|}
\hline Variable & Units & Mean & Std. Dev. \\
\hline $\begin{array}{l}\text { Expected Phosphorus } \\
\text { reduction }(\mathrm{P})\end{array}$ & $\%$ & 30.745 & 9.979 \\
\hline $\begin{array}{l}\text { Expected Coliform } \\
\quad \text { reduction }(C)\end{array}$ & $\%$ & 24.254 & 9.979 \\
\hline $\begin{array}{l}\text { Half spread around mean } \\
\text { Phosphorus reduction }\end{array}$ & $\%$ & 9.979 & 7.811 \\
\hline $\begin{array}{l}\text { Half spread around mean } \\
\text { Coliform reduction }\end{array}$ & $\%$ & 6.666 & 5.774 \\
\hline $\begin{array}{l}\text { Std. dev. around mean } \\
\text { Phosphorus reduction } \\
\text { (STD_P) }\end{array}$ & $\%$ & 5.951 & 4.631 \\
\hline $\begin{array}{l}\text { Std. dev. around mean } \\
\text { Coliform reduction } \\
\text { (STD_C) }\end{array}$ & $\%$ & 4.036 & 3.444 \\
\hline Farmers' Cost $(\mathrm{F})$ & \$CAD/acre & 3.059 & 7.484 \\
\hline Taxpayers' Cost (T) & \$CAD/acre & 10.596 & 7.983 \\
\hline Age & Year & 48.327 & 14.361 \\
\hline \multirow[t]{6}{*}{ Formal education (edu) $^{\mathrm{a}}$} & - & 3.111 & 0.987 \\
\hline & $\%$ & Primary school = 1 & $4.08 \%$ \\
\hline & $\%$ & Secondary school $=2$ & $23.49 \%$ \\
\hline & $\%$ & High school $=3$ & $37.69 \%$ \\
\hline & $\%$ & University $=4$ & $26.72 \%$ \\
\hline & $\%$ & Post graduate $=5$ & $8.02 \%$ \\
\hline
\end{tabular}

\# of respondents $(711)^{*}$ \# of choice sets $(6) *$ \# of alternatives $(3)=12,798$ observations.

a Mean of education.

The first part of the questionnaire had attitude questions about environmental issues more generally and water quality more specifically. The mean score for perceived media exaggeration of environmental problems is closer to 0 than to 6 at 2.02, but the standard deviation is particularly large at 1.82 (Table 2). The mean score for the self-assessed degree of environmental concern is quite high at 3.70, but it has also a fairly large standard deviation. From these statistics, one can anticipate that observed and unobserved heterogeneities will play important roles in the analysis of the stated choice experiments.

\subsection{Estimation results}

Models grounded in EUT are nonlinear and have been estimated with NLogit 5's nonlinear random parameter logit estimator. Two types of risk preferences are considered. Given the nonlinearity of the expected utility functions, model specifications were kept simple and a single interaction variable, education, was included because it was significant in all models. The first type of models posits that respondents have constant absolute risk aversion (CARA). Three different empirical versions of Eq. (1) were then estimated and the results were presented in the first three columns of Table 3. Results in the first column pertain to a specification with random risk preference parameters interacting with education. In the case of coliforms, the Arrow-Pratt coefficient of absolute risk aversion (ARA) is $\widehat{\gamma}_{c} \equiv \gamma_{c}+\gamma_{c, \text { educ }} *$ educ. The coefficient $\gamma_{c}$ is normally distributed with a mean of 0.08 , that is not statistically different from zero, but the coefficient $\gamma_{c, \text { educ }}=0.06$ is highly significant. This implies that rural residents are risk averse when it comes to possible deviations around expected coliform reductions and that absolute risk aversion is increasing with education. The standard deviation of coliforms STD $\gamma_{c}=0.28$ is highly significant and its size confirms that there is much unobserved heterogeneity in the degree of risk aversion across rural residents. ${ }^{19}$ As for phosphorus, the coefficient $\gamma_{p, e d u c}$ is positive and statistically significant, $\gamma_{p}$ is not statistically significant, but STD $\gamma_{p}$ is. Thus for both coliform and phosphorus, risk aversion is increasing with the level of education and unobserved heterogeneity matters in the conditioning of risk preferences. Having taxpayers and farmers pay to achieve water quality improvements, all else equal, significantly decreases utility of respondents as $\beta_{\cos t, t}$ and $\beta_{\cos t, f}$ are negative and highly significant. The magnitude of these cost coefficients play an important role in the analysis of the tradeoffs between costs and expected reductions in coliforms and phosphorus discussed in the subsection on willingness-to-pay estimates.

The results appearing in the second column are from a model that posits that mean risk aversion is the same whether risk pertains to coliform or phosphorus reductions. The parameters that do not pertain to mean risk aversion are robust to the constraint as they are very close to the ones reported in the first column, but a likelihood ratio test $2(-3896+3903)=14>\chi_{3,0.05}^{2}=7.82$ implies the rejection of the restricted model (i.e., $H_{0}: \gamma_{c}=\gamma_{p}$, $\gamma_{c, \text { educ }}=\gamma_{p, \text { educ }}$, STD $_{\gamma_{c}}=S T D_{\gamma_{p}}$ ).

The third CARA model assumes that all residents have the same risk parameters. The mean risk-aversion parameters are nonrandom and do not interact with education. The risk aversion parameters differ significantly $\gamma_{c}=0.24>0.05=\gamma_{p}$ which suggests that rural residents are more risk averse when risk is about coliform reductions than when phosphorus reductions are considered. This might reflect a greater concern for health risks than for environmental ones. The third CARA model has random cost coefficients allowed to interact with education. An exponential transformation was performed to insure that costs have strictly negative effects on utility. The rationale for random costs is that different individuals might have different views about who should pay for water quality improvements. As expected, the mean cost coefficients are negative and significant. The costs-education interaction effect is significantly different from zero for taxpayers' costs and this implies that more highly educated residents are less inconvenienced by having taxpayers and farmers coerced into financially contributing to water quality improvements. This third CARA model has the same

\footnotetext{
19 The range defined by $\gamma_{c}+\gamma_{c, \text { educ }} * e d u c \pm 1.96 * S T D \gamma_{c}$ spans negative values which should be censored at zero to insure that the expected utility is not decreasing in mean coliform reductions. Replacing $\gamma_{c}$ by $e^{\gamma_{c}}$ is a way to avoid negative values, but attempts to impose this restriction failed. However, exponential transformations were successfully used to insure that random cost effects are strictly negative.
} 
Table 3

Expected utility CARA and CRRA models.

\begin{tabular}{|c|c|c|c|c|c|c|}
\hline Coefficients & CARA(1) & $\operatorname{CARA}(2)$ & CARA(3) & CRRA(4) & CRRA(5) & $\operatorname{CRRA}(6)$ \\
\hline$\gamma_{c}$ & $0.0837(0.0972)$ & $0.0095(0.0592)$ & $0.2420^{* * *}(0.0688)$ & $0.0220(0.0738)$ & $0.3542^{* * *}(0.0373)$ & $0.3570^{* * *}(0.0366)$ \\
\hline$\gamma_{c, e d u c}$ & $0.0610 *(0.0335)$ & $0.0752^{* * *}(0.0219)$ & - & $0.1177^{* * *}(0.0176)$ & - & - \\
\hline STD $\gamma_{c}$ & $0.2851^{* * *}(0.0587)$ & $0.2836^{* * *}(0.0408)$ & - & - & - & - \\
\hline$\gamma_{p}$ & $-0.1055(0.1176)$ & $0.0095(0.0592)$ & $0.0513 *(0.0290)$ & $0.4713^{* * *}(0.1006)$ & $0.4825^{* * *}(0.0589)$ & $0.4813^{* * *}(0.0582)$ \\
\hline$\gamma_{p, \text { educ }}$ & $0.0757^{* * *}(0.0218)$ & $0.0752^{* * *}(0.0219)$ & - & $0.0239(0.0210)$ & - & - \\
\hline STD $\gamma_{p}$ & $0.2380^{* * *}(0.0695)$ & $0.2836^{* * *}(0.0408)$ & - & $0.1414^{* * *}(0.0519)$ & - & - \\
\hline$\beta_{\cos t, t}$ & $-0.2055^{* * *}(0.0413)$ & $-0.2137^{* * *}(0.0409)$ & $-1.0904^{*}(0.6387)$ & $-0.3423^{* * *}(0.0433)$ & $-0.6677^{* * *}(0.1137)$ & $-0.7035^{* * *}(0.0982$ \\
\hline$\beta_{\cos t, t, e d u c}$ & - & - & $0.6426^{* *}(0.2637)$ & - & $0.1146^{* * *}(0.0360)$ & $0.1251^{* * *}(0.0307)$ \\
\hline $\operatorname{STD} \beta_{\cos t, t}$ & - & - & $1.7203^{* * *}(0.3037)$ & $-0.1489^{* * *}(0.0211)$ & $0.2890^{* * *}(0.0801)$ & $0.1884^{* *}(0.0935)$ \\
\hline$\beta_{\cos t . f}$ & $-0.1578^{* * *}(0.0203)$ & $-0.1580^{* * *}(0.0203)$ & $-1.7565^{* * *}(0.4178)$ & - & $-0.2222^{* * *}(0.0645)$ & $-0.1414^{* * *}(0.0214)$ \\
\hline$\beta_{\cos t, f, e d u c}$ & - & - & $-0.17395(0.12857)$ & - & $0.0284(0.0195)$ & - \\
\hline $\operatorname{STD} \beta_{\cos t . f}$ & - & - & $0.76977^{* * *}(0.18113)$ & - & $0.20191^{* * *}(0.04269)$ & - \\
\hline Constant & $1.8626^{* * *}(0.1477)$ & $1.7203^{* * *}(0.1553)$ & $1.27840^{* * *}(0.13319)$ & $-4.4567^{* * *}(0.1670)$ & $-4.0634^{* * *}(0.1733)$ & $-4.1238^{* * *}(0.1663)$ \\
\hline LLF & -3896 & -3903 & -4025 & -4504 & -4521 & -4536 \\
\hline McFadden $\mathrm{R}^{2}$ & 0.17 & 0.17 & 0.14 & 0.04 & 0.04 & 0.03 \\
\hline
\end{tabular}

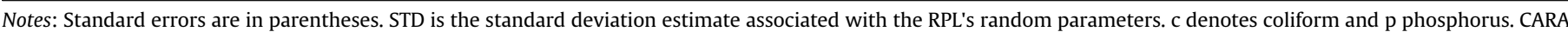
denotes constant absolute risk aversion while CRRA stands for constant relative risk aversion. cost,f represents farmers' cost while cost,t stands for taxpayers' cost.

${ }^{* * *},{ }^{* *},{ }^{*}=$ Significance at $1 \%, 5 \%, 10 \%$ level.

number of parameters as the first one, but it does not fit the data as well.

The last three columns in Table 3 feature estimation results for CRRA (constant relative risk aversion) models. All three models have significant constant relative aversion CRA coefficients. The fourth column features a model with a random risk coefficient for phosphorus $\left(\gamma_{p}\right)$ and a fixed risk coefficient for coliforms $\left(\gamma_{c}\right)$. This specification came about after experimenting with more general specifications. The CRA coefficient for phosphorus varies between 0.19 and 0.75 because of unobserved heterogeneity (i.e., $\left.\widehat{\gamma}_{p}=0.47 \pm 1.96 * 0.14\right)$, but it does not vary with education. In contrast, the non-random CRA coefficient for coliforms varies between 0.12 and 0.48 depending on the level of education (i.e., $\left.\widehat{\gamma}_{c}=0.12^{*} e d u c\right)$. The cost parameters are statistically significant and have the right sign. The fit is actually slightly better than the fit of the model in the fifth column which has two random cost parameters but non-random risk aversion parameters. This suggests that heterogeneity in risk aversion is more important that heterogeneity in costs. The sixth and last column has a model with a single random cost parameter. Clearly, this last model is misspecified, but the risk and mean cost coefficients are very close to their counterparts in the fifth column and this attests of the robustness of the results. Amongst CRRA models, the one with a random risk coefficient fits the data best, but its log likelihood is not as high as that of CARA models. It can be concluded that empirical support is stronger for CARA risk preferences than for CRRA risk preferences amongst expected utility models.

\subsection{Willingness to (have taxpayers or farmers) pay for expected reductions in coliforms and phosphorus}

Willingness-to-Pay (WTP) estimates are typically computed as the negative of the ratio of the coefficient for an attribute of interest and the coefficient of a monetary variable when the utility function is linear in the parameters. With the CARA expected utility function depicted in Eq. (1), WTP can be derived in a similar manner:

$$
W T P_{r_{k} c_{n}}=-\frac{\mathrm{e}^{-\gamma_{k}\left(r_{k}+d_{k}\right)}\left(1+\mathrm{e}^{\gamma_{k} d_{k}}+\mathrm{e}^{2 \gamma_{k} d_{k}}\right) \gamma_{k}}{3 \beta_{\cos t, n}} ; k=p, c ; n=t, f
$$

WTP estimates can be computed at specific mean reduction $\left(r_{k}\right)$ and deviation $\left(d_{k}\right)$ for phosphorus and coliforms and with respect to cost for taxpayers $(n=t)$ or farmers $(n=f)$. WTP in (3) depends on only two estimated coefficients $\left(\beta_{\cos t, n}, \gamma_{k}\right)$ in the absence of observed and unobserved heterogeneity. In models with education interacting with costs (i.e., CARA (3) and CRRA (6)), WTP increases (decreases) with education if the interaction coefficient is positive (negative). When the risk parameter is allowed to have a direct effect and an interaction effect with education, parameter $\gamma_{k}$ must be replaced with $\gamma_{k}+\gamma_{k \text {,educ }}{ }^{*}$ education to handle observed heterogeneity. WTP is increasing in the level of absolute risk aversion and in the size of the deviations $d_{k}$ around the expected mean reductions.

When respondents are assumed to behave according to CRRA risk preferences, their WTP based on Eq. (2) is:

$W \operatorname{WP}_{r_{k} c_{n}}=-\frac{r_{k}^{-\gamma_{k}}+\left(r_{k}-d_{k}\right)^{-\gamma_{k}}+\left(r_{k}+d_{k}\right)^{-\gamma_{k}}}{3 \beta_{\cos t, n}} ; k=p, c ; n=t, f$

Parameters treated as random are also interacting with education and this is implicit in the definitions of $\gamma_{k}$ and $\beta_{\cos t, n}$. WTP estimates are computed by replacing random parameters in the WTP formulas by 10,000 draws from the distributions of the random parameters. The resulting empirical distributions can then be used to generate measures of central tendency and dispersion for WTPs.

The WTPs measure the financial burdens that rural residents are willing to impose on themselves and other taxpayers and farmers to secure water quality improvements. Who should pay for water quality improvements is the sort of question that elicited different viewpoints when the pre-test for this study was conducted. Some view agriculture as a major cause of water quality degradation and would like the polluter-payer principle enforced. However, Ellison et al. (2010) found that US taxpayers generally support farm subsidies, especially for small farms, even when they believe that these farm families enjoy a higher income than their own household. Their support for farm subsidies is rooted in concerns over food security. In the survey, some non-farm resident respondents indicated that farmers had to financially contribute more to improve the environment, but $70 \%$ of the sample believes that food prices would be higher if farm subsidies were reduced.

The implied WTP results in terms of taxpayers' cost and farmers' cost are computed for different models and are summarized in 
Table 4

Willingness to have taxpayers or farmers pay (\$CAD) for coliform and phosphorus reductions.

\begin{tabular}{lllll}
\hline & CARA(1) & CARA(2) & CARA(3) & CRRA(4) \\
\hline WTP $_{c, t}$ & $0.68[0-1.26]$ & $0.78[0-1.28]$ & $6.86[0.76-60.61]$ & $3.36-$ \\
WTP $_{\mathrm{p}, \mathrm{t}}$ & $0.48[0-1.12]$ & $0.78[0-1.17]$ & $1.90[0.21-16.78]$ & $3.62[3.34-3.94]$ \\
$\mathrm{WTP}_{\mathrm{c}, \mathrm{f}}$ & $0.92[0-1.69]$ & $1.05[0-1.73]$ & $0.85[0.32-2.30]$ & $7.73-$ \\
$\mathrm{WTP}_{\mathrm{p}, \mathrm{f}}$ & $0.65[0-1.51]$ & $1.05[0-1.73]$ & $0.23[0.09-0.63]$ & $8.32[7.69-9.06]$ \\
\hline
\end{tabular}

The median is the first entry. Ranges for WTPs are in brackets. The lower bound is max. $[0,0.1$ quantile] while the upper bound in the 0.9 quantile. Education was set at 3 (its mean value), and $r_{k}, \sigma_{k}$ were set at 1.5 and 1 , respectively. 10,000 sets of parameters were drawn from the distributions of random parameters to compute the simulated WTPs.

Table 4. Median values are reported because the median is a more robust measure of central tendency. It is less influenced by outliers and it can be related to a majority voting rule (Bateman et al., 2002 p. 194). The first column of WTP estimates is associated with the CARA (1) model. The second column shows WTPs from the CARA (2) model which assumes that risk aversion parameters for coliforms and phosphorus are identical. Therefore, the numerator in (3) is the same for coliforms and phosphorus and it incorporates a random parameter. Because marginal utility from coliform and phosphorus reductions must be weakly positive, the interval was trimmed on the left side to insure that the lower bound does not fall below zero. ${ }^{20}$ However, such transformations induce very long tails that inflate the upper bound as can be shown in the WTP results for CARA (3) whose costs parameters were replaced by exponential transformations in the estimation.

According to the preferred CARA (1) model with random risk aversion parameters, the median rural residents would be willing to impose a financial burden of $\$ 0.68$ CAD on each taxpayer in order to secure a $10 \%$ reduction in coliforms. To put things in perspective, the contribution of Quebec taxpayers would be able to fund $\$ 20.4$ million CAD program for a $50 \%$ drop that would see the coliform count fall from 300 to 150 organisms (i.e., from "fishable water" to "swimmable water"). The corresponding WTP estimate from the CARA (2) model is quite similar, but the ones from the CARA (3) and CRRA (4) are much higher with median respondents willing to have each Quebec taxpayer pay $\$ 6.86$ CAD and $\$ 3.36$ CAD for a $10 \%$ reduction in coliforms. Phosphorus reductions are not as valuable as coliform reductions, except under the CRRA (4) model. Median WTP estimates range from $\$ 0.48$ CAD to $\$ 3.62$ CAD for a $10 \%$ reduction in phosphorus concentration. The relatively high WTP for phosphorus reductions suggest that rural residents derive direct benefits from such reductions. Yao et al. (2014) found that people living within an area where investment would be made to preserve biodiversity have higher WTP than people living outside the area. The high WTP may also reflect concerns for farmers whose participation in the main income-support program in Quebec requires phosphorus monitoring.

The median resident in the CARA (1) model is willing to impose on farmers a cost of $\$ 0.92$ CAD per acre for a $10 \%$ reduction in the coliform and \$0.65 CAD per acre for an equally large reduction in phosphorus. The WTPs under the CARA (2) and CARA (3) models are quite similar for coliforms ( $\$ 1.05 \mathrm{CAD}$ and $\$ 0.85 \mathrm{CAD}$ ), but there are larger differences across models for phosphorus even if one discards the CRRA (4) estimate as unreasonably high. The CARA WTP estimates range from $\$ 0.23$ CAD to $\$ 1.05$ CAD. To put things in perspective, Gitau et al. (2004) estimated the lowest possible cost to implement a $60 \%$ reduction in phosphorus on a typical New York

\footnotetext{
${ }^{20}$ Attempts to estimate the model with exponential transformations of risk parameters did not succeed.
}

farm at around \$3 CAD per acre. ${ }^{21}$ The WTP estimate from the CARA (1) model for a $60 \%$ phosphorus reduction indicate that the middle rural resident would let farmers pay the whole cost and then some $\left(\$ 0.65^{*} 6=\$ 3.30\right.$ CAD). However, the lower WTP from the CARA (3) model suggests that the middle rural resident would want farmers to pay only part of the full cost to achieve a $60 \%$ phosphorus reduction. Since the CARA (1) model fits the data better than CARA (3), it can be inferred that at least half of the rural residents in our sample would want to see farmers pay the full cost of BMPs. Nevertheless, WTP estimates vary much across respondents as they reflect variations in objective and subjective concerns and values across residents.

The pay-the-polluter principle has been criticized for its ineffectiveness in solving the "phosphorus puzzle" by Garnache et al. (2016) who advocate a swing toward the polluter-payer principle. The above results show that non-farm rural residents support government subsidies provided that phosphorus and coliform reductions be actually achieved. This is in line with the results of Gitau et al. (2004). As in Polyzou et al. (2011), rural residents endowed with higher social capital are willing to see higher contributions from taxpayers. However, they also favor increasing the financial burden of farmers to secure water quality improvements. This provides more scope for departing from voluntary cost-share programs currently in fashion. Governments in industrialized countries subsidize agriculture and are hesitant to consider taxes and costly regulations to internalize negative externalities associated with agricultural production. This is likely to change as the weight of non-farm rural residents increase relative to that of farmers.

\section{Concluding remarks}

Excess phosphorus in the Chaudière region south of Quebec City in Canada has spurred opposition toward large scale hog operations, bringing together environmental groups, local businesses and residents in demanding stricter environmental regulations to reduce health and environmental hazards and adverse effects on tourism and recreation. As the number of farmers is shrinking, policy makers are increasingly attentive to the needs of other rural residents and this is why the aim of study is to investigate the valuation of water quality improvements in the form of phosphorus and coliform reductions by non-farm rural residents. One of the objectives of this study is to assess the extent by which dispersion around expected pollution reductions might impact on the value of expected reductions. A second objective is to characterize the nature and degree of risk aversion amongst rural residents when it comes to water quality. A third objective has to do with the estimation of the financial contributions of farmers and taxpayers to secure water quality improvements.

Choice experiments were used to gather information about the preferences of rural residents which were analyzed with random utility models allowing for risk. Even though confidence intervals around environmental outcomes, including BMP performance, can be wide, few studies have explicitly accounted for risk. Random utility models featuring either constant absolute risk aversion (CARA) or constant relative risk aversion (CRRA) were estimated and heterogeneity in the degree of risk aversion amongst residents was dealt with by having interaction effects and random parameters. A stated preference design made up of 12 choice sets blocked into two small designs was developed to have each respondent

\footnotetext{
21 The cost was US\$1700 for a 300 ha/744 acre farm. Using a farm input price index (cansim table 328-0015) and an exchange rate of 0.78 gave us an estimate in 2016 Canadian dollars.
} 
confronted to six choice sets. The purpose was to insure that respondents would take the time to properly evaluate the trade-offs between expected pollution reductions, deviations around mean reductions and costs imposed on taxpayers and farmers. Dispersion was directly incorporated into the choice sets through a three-point uniform distribution describing the expected reductions as well as deviations from the mean. The paper focused on coliforms and phosphorus reductions because many rural residents have their well water tested for coliforms on a regular basis and because much of the provincial government's changes in agricultural and environmental policies and regulations have focused on phosphorus.

The estimations indicate that CARA models perform better than CRRA models. As expected, the degree of risk aversion amongst rural residents is increasing with education and varies in relation to unobservable factors. Risk aversion implies that expected reductions in pollutants are valued less in the presence of dispersion around expected reductions. As in Polyzou et al. (2011), rural residents endowed with higher social capital are willing to see the government use higher taxes to secure water quality improvements. They are also willing to see the government ask more from farmers. Voluntary cost-share programs in Quebec and elsewhere have been ineffective and Garnache et al. (2016) argue for a change in paradigm. In Quebec as in most of the industrialized world, it has been difficult to reduce agricultural subsidies and farm programs because of public support. However, our results suggest that more can be asked from farmers when it comes to securing water quality improvements. Interestingly, the odds of a switch to a polluterpayer paradigm are likely to improve over time because the political weight of non-farm rural residents is on the rise. Also, the risk of investing in underperforming practices and technologies should be reduced as the science around water quality improves.

For future research, it would be useful to focus on the preferences of city residents to determine whether distance impacts on willingness-to-pay for water quality in rural areas. ${ }^{22}$ While task complexity is always a concern in stated choice experiments, it might be interesting to depart from the uniform distribution and allow different water quality outcomes to have different probabilities. Different types of behavior under risk could then be tested for. Finally, results from stated choice experiments are subject to the so-called hypothetical bias (i.e., what people say and what they do may differ). There is a rapidly growing literature on how cheap talk, honesty priming and other mitigating strategies can be used to get more reliable results (e.g., Bello and Abdulai, 2016; Whitehead et al., 2016). While precautions were taken to minimize the hypothetical bias, our results remain subject to the usual caveat.

\section{Acknowledgments}

Funding for this study was provided by Agriculture and Agrifood Canada's Watershed Evaluation of Beneficial Management Practices (WEBs) program and the Fonds Québécois de la Recherche sur la Société et la Culture (FQRSC). The authors are grateful to Jornette Dangbedji for her assistance during questionnaire design and data collection and to hydrology expert Prof. Alain Rousseau.

\section{References}

Asci, S., Borisova, T., VanSickle, J.J., 2015. Role of economics in developing fertilizer best management practices. Agric. Water Manag. 152, 251-261.

Bateman, I.J., Carson, R.T., Day, B., Hanemann, M., Hanley, N., Hett, T., Jones-Lee, M., Loomes, G., Mourato, S., Özdemiroğlu, E., Obe, D.W.P., Sugden, R., Swanson, J.,

\footnotetext{
22 Water contamination is a concern among city dwellers too. In the recent case in Flint (Michigan), lead leaked from aging pipes and thousands of children were found to have elevated levels of lead in their blood.
}

2002. Economic Valuation with Stated Preference Techniques. Edward Elgar Publishing Limited, Cheltenham, UK, p. 457.

Baumgart-Getz, A., Prokopy, L.S., Floress, K., 2012. Why farmers adopt best management practice in the United States: a meta-analysis of the adoption literature. J. Environ. Manag. 96, 17-25.

Bello, M., Abdulai, A., 2016. Impact of Ex-Ante hypothetical bias mitigation methods on attribute non-attendance in choice experiments. Am. J. Agric. Econ. 98, 1486-1506.

Brehm, J.M., Pasko, D.K., Eisenhauer, B.W., 2013. Identifying key factors in Homeowner's adoption of water quality best management practices. Environ. Manag. 52, 113-122.

Campbell, D., Vedel, S.E., Thorsen, B.J., Jacobsen, J.B., 2013. Heterogeneity in the WTP for recreational access: distributional aspects. J. Environ. Plan. Manag. http:// dx.doi.org/10.1080/09640568.2013.793173.

Colombo, S., Hanley, N., Louviere, J., 2009. Modeling preference heterogeneity in stated choice data: an analysis for public goods generated by agriculture. Agric. Econ. 40, 307-322.

Colombo, S., Glenk, K., Rocamora-Montiel, B., 2016. Analysis of choice inconsistencies in on-line choice experiments: impact on welfare measures. Eur. Rev. Agric. Econ. 43, 271-302.

Ellison, B.D., Lusk, J., Briggeman, B.C., 2010. Taxpayer beliefs about farm income and preferences for farm policy. Appl. Econ. Perspect. Policy 32, 338-354.

Garnache, C., Swinton, S.M., Herriges, J.A., Lupi, F., Stevenson, J., 2016. Solving the phosphorus pollution puzzle: synthesis and directions for future research. Am. J. Agric. Econ. 98, 1334-1339.

Ghazalian, P.L., Larue, B., West, G.E., 2009. Best management practices to enhance water quality: who is adopting them? J. Agric. Appl. Econ. 41, 663-682.

Ghazalian, P.L., Larue, B., West, G.E., 2010. Best management practices and the production of good and bad outputs. Can. J. Agric. Econ. 58, 283-302.

Gitau, M.W., Veith, T.L., Gburek, W.J., 2004. Farm-level optimization of BMP placement for cost-effective pollution reduction. Trans. Am. Soc. Agric. Eng. 47 (6), 1923-1931.

Glenk, K., Colombo, S., 2013. Modeling outcome-related risk in choice experiments. Aust. J. Agric, Resour. Econ, 57, 559-578.

Hadrich, J.C., Van Winkle, A., 2013. Awareness and pro-active adoption of surface water BMPs. J. Environ. Manag. 127, 221-227.

Hanley, N., Colombo, S., Tinch, D., Black, A., Aftab, A., 2006. Estimating the benefits of water quality improvements under the water framework directive: are benefits transferable? Eur. Rev. Agric. Econ. 33, 391-413.

Hensher, D.A., Rose, J., Greene, W.H., 2005. The implications on willingness to pay of respondents ignoring specific attributes. Transportation 32, 203-222.

Hirshleifer, J., Riley, J.G., 1992. The Analytics of Uncertainty and Information. Cambridge University Press, New York.

Kosenius, A.K., 2010. Heterogeneous preferences for water quality attributes: the case of eutrophication in the Gulf of Finland, the baltic sea. Ecol. Econ. 69, $528-538$.

Lathrop, R.C., Carpenter, S.R., Stow, C.R., Soranno, P.A., Panuska, J.C., 1998. Phosphorus loading reductions needed to control blue-green alga blooms in Lake Mendota. Can. J. Fish. Aquat. Sci. 55, 1169-1178.

Louviere, J.J., Hensher, D.A., Swait, J.D., 2000. Stated Choice Methods: Analysis and Application. Cambridge University Press, Cambridge, 402pp.

Luzar, J.E., Cossé, K.J., 1998. Willingness to pay or intention to pay: the attitudebehavior relationship in contingent valuation. J. Socio Econ. 27, 427-444.

McFadden, D., Train, K., 2000. Mixed MNL models for discrete response. J. Appl. Econ. 15, 447-470.

MDDEP (Ministère du Développement Durable, de l'Environement et des Parcs, Québec), 2011a. Politique Nationale de l'Eau. L'Eau-La Vie-L'Avenir, p. 126.

MDDEP (Ministère du Développement Durable, de l'Environement et des Parcs, Québec), 2011b. Water Governance Reform: a Strategic Choice. http://www. mddelcc.gouv.qc.ca/eau/politique/index-en.htm\#integrated (Accessed 9 December 2016).

Meals, D.W., Dressing, S.A., Davenport, T., 2010. Lag time in water quality response to best management practices: a review. J. Environ. Qual. 39, 85-96.

Michaud, A., Beaudin, I., Deslandes, J., Bonn, F., Modramootoo, A., 2007. SWATpredicted influence of different landscape and cropping system alterations on phosphorus mobility within the pike river watershed of south-Western Quebec. Can. J. Soil Sci. 87, 329-344.

NGene, 2012. NGene 1.1.1 User Manual and Reference Guide. Choice Metrics. http:// choice-metrics.com/index.html.

Palsson, A.M., 1996. Does the degree of relative risk aversion vary with household characteristics? J. Econ. Psychol. 17, 771-787.

Polyzou, E., Jones, N., Evangelinos, K.I., Halvadakis, C.P., 2011. Willingness to pay for drinking water quality improvement and the influence of social capital. J. Socio Econ. 40, 74-80.

Rahelizatovo, N.C., Gillespie, J.M., 2004. The adoption of best-management practices by Louisiana dairy producers. J. Agric. Appl. Econ. 36, 229-240.

Reimer, A.P., Thompson, A.W., Prokopy, L.S., 2012. The multi-dimensional nature of environmental attitudes among farmers in Indiana: implications for conservation adoption. Agric. Hum. Values 29, 29-40.

Rose, J.M., Bleimer, M.C., Henscher, D.A., Collins, A.T., 2008. Designing efficient stated choice experiments in the presence of reference alternatives. Transp. Res. Part B Methodol. 42, 395-406.

Sharpley, A.N., Bergström, L., Aronsson, H., Bechmann, M., Bolster, C.H., Börling, K. Djodjic, F., Jarvie, H.P., Schoumans, O.F., Stamm, C., Tonderski, K.S., Ulén, B., Uusitalo, R., Withers, P.J.A., 2015. Future agriculture with minimized 
phosphorus losses to waters: research needs and direction. Ambio 44, 163-179. Statistics Canada, 2011. Data Products, 2011 Census.

Tamini, L.D., 2011. A nonparametric analysis of the impact of agri-environmental advisory activities on best management practice adoption: a case of Québec. Ecol. Econ. 70, 1363-1374.

Tamini, L.D., Larue, B., West, G.E., 2012. Technical and environmental efficiencies and best management practices in agriculture. Appl. Econ. 44, 1659-1672.

Train, K.E., 2003. Discrete Choice Methods with Simulation. Cambridge University Press, Cambridge, 334 pp.
Valentin, L., Bernardo, D.J., Kastens, T.L., 2004. Testing the empirical relationship between best management practice adoption and farm profitability. Appl. Econ. Perspect. Policy 26, 489-504.

Whitehead, J.C., Weddell, M.S., Groothuis, P.A., 2016. Mitigating hypothetical bias in stated preference data: evidence from sports tourism. Econ. Inq. 54, 605-611.

Yao, R.T., Scarpa, R., Turner, J.A., Barnard, T.D., Rose, J.M., Palma, J.H.N., Harrison, D.R. 2014. Valuing biodiversity enhancement in New Zealand's planted forest: socioeconomic and spatial determinants of willingness-to-pay. Ecol. Econ. 98 90-101. 